\title{
Problems of long-term hospitalised cervical spinal cord injury patients in university hospitals
}

\author{
T Arima MD, ${ }^{1} \mathrm{~T}$ Noguchi MD,${ }^{1} \mathrm{~J}$ Mochida $\mathrm{MD},{ }^{2} \mathrm{E}$ Toh $\mathrm{MD},{ }^{2}$ A Konagai MD ${ }^{2}$ \\ $\mathrm{K}$ Nishimura $\mathrm{MD}^{2}$ \\ ${ }^{1}$ Department of Orthopaedics, Hakone National Hospital, Kanagawa, Japan; ${ }^{2}$ Department \\ of Orthopaedics, Tokai University School of Medicine, Isehara, Kanagawa, Japan.
}

Of the 215 cervical spinal cord injury (CSCI) patients treated in Tokai University Hospital over the last 17 years, 42 who were hospitalised for more than 90 days were selected as the subjects for this survey. They were divided into two groups: group A: patients hospitalised for 180 days or more; and group B: patients hospitalised for more than 90 but less than 180 days. The aspects surveyed were: the number of days of hospitalisation, type of injury, level of spinal cord injury, extent of spinal cord paralysis, assessment based on Frankel's classifications, whether a tracheotomy was performed or not, surgical treatment, complications, and the clinical course after discharge. The most common injury for the 13 patients in group A (average stay 281 days) was a fracture-dislocation, followed next by those with a burst fracture. The majority of the 28 patients in group B (average stay was 117 days) had a central type of spinal cord injury. Characteristics observed in group $\mathrm{A}$ in particular were: higher segment injuries to the cervical spinal cord, complete paralysis, respiratory complications such as pneumonia, tracheotomy, or a waiting time of at least 6 months before discharge, in cases where a transfer to a rehabilitation hospital was possible. The major problems of treating CSCI patients in university hospitals are that severe cases, which are concentrated in university hospitals, are forced to occupy private rooms for long term treatment, and there is a difficulty in transferring these patients to rehabilitation hospitals. The following measures are desirable to improve the situation: construction of facilities specialising in the treatment of spinal cord injuries, and other assertive measures to be taken at national and prefectural levels.

Keywords: cervical spinal cord injury; long term hospitalised patients; repiratory complication; problems in management.

\section{Introduction}

Ideally, university hospitals should treat patients with cervical spinal cord injuries (CSCI) during the acute and subacute phases. However, there are few suitable hospitals to which patients with severe injuries can be transferred and they often require to stay in university hospitals for extended periods. The present survey investigates the actual state of long term hospitalised CSCI patients. The authors will also discuss social measures to improve the situation.

\section{Subjects}

A total of 368 spinal cord injury patients have been treated in our university hospital during the past 17 years, since its establishment in 1975. Of these, 215 patients, or an overwhelming $58.4 \%$, suffered from injuries to the cervical spine. Selected as subjects for 
our survey were 42 CSCI patients who were hospitalised for 90 days or more. They were divided into two groups: group A, hospitalised for 180 days or more (13 patients) and group B, hospitalised for more than 90 days but less than 180 days (29 patients) (Table I).

\section{Results}

Hospitalisation periods for group A patients averaged 281 days, with a maximum of 730 days, while those for group B averaged 117 days. The average age for both groups was between 40 and 49 years. The most common injury for group A patients was a fracturedislocation, followed in frequency by those with a burst fracture, while the largest number of group B patients suffered from central cervical spinal cord injuries (Table II). Sixty percent of group A patients had injuries of the midlevel cervical spinal cord such as $\mathrm{C} 3$ and $\mathrm{C} 4$, while many of the group $B$ patients had injuries of the lower level cervical spinal cord (Table III). The leading cause of injury was a fall (61\% of group A and $48 \%$ of group B patients), followed by traffic accidents.

A majority of group A patients (12 patients, or $92 \%$ ) had complete spinal paralysis. Meanwhile, in group B, although 11 patients had complete paralysis, it should be noted that 18 patients $(62 \%)$ had partial paralysis. Complete paralysis did not improve in either group, based on Frankel's classification. While six group A patients $(46 \%$, indicating a large number of nonfunctional cases) required tracheotomy and mechanical ventilation after admission, only six group B patients $(20 \%)$ received this treatment.

Seventy percent of group A patients (nine patients) and $49 \%$ of group B patients (14 patients) had surgical treatment, suggesting that group A patients received surgical operations more often, in accordance with a greater degree of bone injury. No significant differences were seen between the two groups in terms of the type of surgery performed, except that the posterior method with wiring (for dislocations), as well as the Luque method (for the unstable spine), and anterior spinal fusion were frequently used for patients with fracturedislocations. The anterior method was frequently used for subtotal vertebrectomy in burst fracture cases. Vertebral body wiring was added in some cases. ${ }^{1}$

The commonest complication for both groups was pneumonia, experienced by $53 \%$ of group A patients. In addition, some patients had multiple complications such as decubitus ulcers, cystitis, and gastrointestinal haemorrhages (Table IV).

\section{Discharge}

Sixty percent of group A patients managed to be transferred to rehabilitation hospitals in Kanagawa or other prefectures after waiting for at least 6 months. Two patients were discharged and sent home directly, two died during hospitalisation, and one is still hospitalised after 2 years. A large number of group B patients were transferred to rehabilitation hospitals in Kanagawa within 6 months, and the rest were discharged and remain at home.

\section{Case report}

A 56 year old male patient, who fell while at work, sustained an excessive stretch injury which resulted in paralysis at the level of $\mathrm{C} 4$. $\mathrm{X}$-rays showed no fracture although the patient had an ossitication of posterior longitudinal ligament (OPLL) complication and swelling in the posterior pharynx. To date, the patient remains paralysed and has been hospitalised for 730 days. He has a tracheotomy, and requires mechanical ventilation. Monthly hospital expenses amounting to more than one million yen are covered by the Workmen's Accident Compensation Insurance. However, the patient pays for a private room, which costs him more than 200,000 yen a month (Fig 1).

\section{Discussion}

Each year, between 30 and 40 spinal cord injury patients are admitted to our university hospital, a majority of whom suffer from CSCI.

During the acute phase of treatment, CSCI patients first enter the intensive care unit, then are transferred to general wards. Orthopaedic treatment during this period consists of installing halo-tong traction for 
Table I Details of group A (13 cases hospitalised for more than 180 days)

\begin{tabular}{|c|c|c|c|c|c|c|c|c|c|c|}
\hline Patient & Age/Sex & $\begin{array}{l}\text { Days in } \\
\text { hospital }\end{array}$ & $\begin{array}{l}\text { Cause of } \\
\text { injury }\end{array}$ & Diagnosis & $\begin{array}{l}\text { Degree of } \\
\text { paralysis }\end{array}$ & $\begin{array}{l}\text { Frankel } \\
\text { grade }\end{array}$ & Treatment & Surgery & Complications & Discharge \\
\hline 1 & $56 / \mathrm{M}$ & 730 & Fall & $\begin{array}{l}\text { C4 hyperextension } \\
\text { injury }\end{array}$ & C4 complete & $A-A$ & Tracheotomy & - & Pncumonia & Hospital \\
\hline 2 & $54 / \mathrm{M}$ & 518 & Fall & $\begin{array}{l}\mathrm{C} 4 \text { fracture- } \\
\text { dislocation }\end{array}$ & C5 complete & $\mathrm{A}-\mathrm{A}$ & Trachcotomy & PR & Pncumonia & Dicd \\
\hline 3 & $24 / F$ & 294 & Fall & $\begin{array}{l}\mathrm{C} 4 \text { fracture- } \\
\text { dislocation }\end{array}$ & C5 complete & $A-A$ & Tracheotomy & $\mathrm{PR}+\mathrm{ASF}$ & Decubitus ulcer & $\begin{array}{l}\text { Rehabilitation } \\
\text { centre }\end{array}$ \\
\hline 4 & $70 / \mathrm{M}$ & 285 & Fall & $\begin{array}{l}\text { C5 fracture- } \\
\text { dislocation }\end{array}$ & C6 complete & $\mathrm{A}-\mathrm{A}$ & Tracheotomy & $\mathrm{PR}+\mathrm{ASF}$ & Pncumonia & Died \\
\hline 5 & $16 / F$ & 252 & $\begin{array}{l}\text { Traffic } \\
\text { accident }\end{array}$ & C5 burst fracture & C4 complete & $A-A$ & Tracheotomy & $\mathrm{Lu}+\mathrm{ASF}$ & Hacmothorax & $\begin{array}{l}\text { Rehabilitation } \\
\text { centre }\end{array}$ \\
\hline 6 & $58 / \mathrm{M}$ & 218 & Fall & C5 burst fracture & C5 complete & $A-A$ & - & ASF & $\begin{array}{l}\text { Gastrointestinal } \\
\text { blecding }\end{array}$ & Home \\
\hline 7 & $44 / \mathrm{M}$ & 211 & Fall & C6 burst fracture & C6 complete & $A-A$ & - & ASF & Pncumonia & $\begin{array}{l}\text { Rehabilitation } \\
\text { centre }\end{array}$ \\
\hline 8 & $31 / \mathrm{M}$ & 210 & $\begin{array}{l}\text { Sports } \\
\text { accident }\end{array}$ & C4 burst fracture & C4 complete & $\mathrm{A}-\mathrm{A}$ & - & Lu & $\begin{array}{l}\text { Gastrointestinal } \\
\text { bleeding }\end{array}$ & $\begin{array}{l}\text { Rehabilitation } \\
\text { centre }\end{array}$ \\
\hline 9 & $16 / \mathrm{M}$ & 209 & $\begin{array}{l}\text { Sports } \\
\text { accident }\end{array}$ & C5 burst fracture & C5 complete & $\mathrm{A}-\mathrm{A}$ & - & $\mathrm{PR}+\mathrm{ASF}$ & Cystitis & $\begin{array}{l}\text { Rehabilitation } \\
\text { centre }\end{array}$ \\
\hline 10 & 49/M & 207 & Fall & $\begin{array}{l}\text { C4 hyperextension } \\
\text { injury }\end{array}$ & C6 incomplete & $\mathrm{B}-\mathrm{B}$ & - & - & Decubitus ulcer & $\begin{array}{l}\text { Rehabilitation } \\
\text { centre }\end{array}$ \\
\hline 11 & $43 / \mathrm{M}$ & 185 & Fall & $\begin{array}{l}\text { C4 fracture- } \\
\text { dislocation }\end{array}$ & C5 complete & $\mathrm{A}-\mathrm{A}$ & Tracheotomy & PR & Pneumonia & $\begin{array}{l}\text { Rehabilitation } \\
\text { centre }\end{array}$ \\
\hline 12 & $77 / \mathrm{M}$ & 184 & Fall & $\begin{array}{l}\text { C3 hyperextension } \\
\text { injury }\end{array}$ & C3 complete & $A-A$ & Tracheotomy & - & Pneumonia & $\begin{array}{l}\text { Rehabilitation } \\
\text { centre }\end{array}$ \\
\hline 13 & $29 / \mathrm{M}$ & 184 & $\begin{array}{l}\text { Traffic } \\
\text { accident }\end{array}$ & $\begin{array}{l}\mathrm{C} 4 \text { fracture- } \\
\text { dislocation }\end{array}$ & C4 complete & $A-B$ & Intubation & ASF & $\begin{array}{l}\text { Dislodging of } \\
\text { grafting bone }\end{array}$ & $\begin{array}{l}\text { Rehabilitation } \\
\text { centre }\end{array}$ \\
\hline
\end{tabular}

$\mathrm{PR}=$ posterior reduction; $\mathrm{ASF}=$ anterior spinal fusion; $\mathrm{Lu}=$ Luque rod. 
Table II Spinal injuries in groups A and B

\begin{tabular}{lcr}
\hline & Group A & Group B \\
\hline Fracture-dislocation & $6(46.2 \%)$ & $7(24.1 \%)$ \\
Burst fracture & $4(30.8 \%)$ & $8(27.6 \%)$ \\
Hyperextension injury & $3(23.0 \%)$ & $2(6.9 \%)$ \\
Central spinal cord injury & 0 & $12(41.4 \%)$ \\
Total & 13 & 29 \\
\hline
\end{tabular}

Table III Levels of spinal cord injuries in groups A and B

Table IV Complications in groups A and B

\begin{tabular}{lcr}
\hline Level & Group A & \multicolumn{1}{c}{ Group B } \\
\hline C3 & $1(7.7 \%)$ & 0 \\
C4 & $7(53.8 \%)$ & $1(3.4 \%)$ \\
C5 & $3(23.0 \%)$ & $12(41.3 \%)$ \\
C6 & $2(15.4 \%)$ & $8(27.5 \%)$ \\
C7 & 0 & $5(17.2 \%)$ \\
C8 & 0 & $3(10.3 \%)$ \\
Total & 13 cases & 29 cases \\
\hline
\end{tabular}

\begin{tabular}{lcr}
\hline & Group A & Group B \\
\hline Pneumonia & $7(53.8 \%)$ & $11(37.9 \%)$ \\
Decubitus ulcer & $5(38.4 \%)$ & $4(13.8 \%)$ \\
Cystitis & $2(15.4 \%)$ & $4(13.8 \%)$ \\
Gastrointestinal & & \\
$\quad$ bleeding & $2(15.4 \%)$ & 0 \\
Heart failure & $1(7.7 \%)$ & $1(3.5 \%)$ \\
Multitrauma & $1(7.7 \%)$ & $5(17.2 \%)$ \\
Reduction failure & $2(15.4 \%)$ & 0
\end{tabular}

Total

13 cases

29 cases

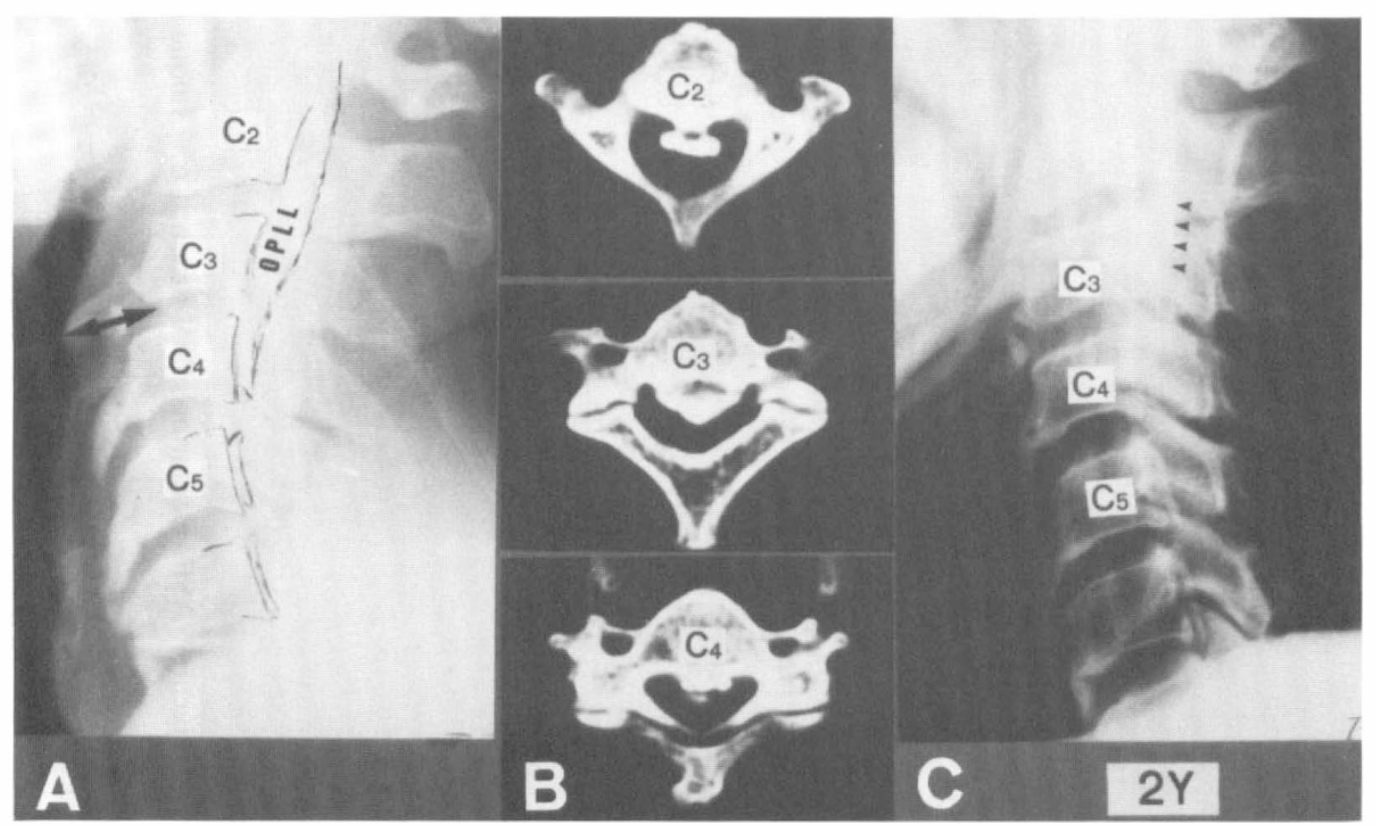

Figure 1 A 56 year old man with C4 complete paralysis hyperextension injury at C3-4 with OPLL, hospitalised for 730 days. (A) X-ray on admission revealed swelling of retropharyngeal space (arrow). (B) CT on admission revealed no fracture, but OPLL at C2-C4. (C) X-ray 2 years after injury. 
Table $\mathbf{V}$ Acute-phase treatment system for cervical spinal cord injury patients at Tokai University Hospital

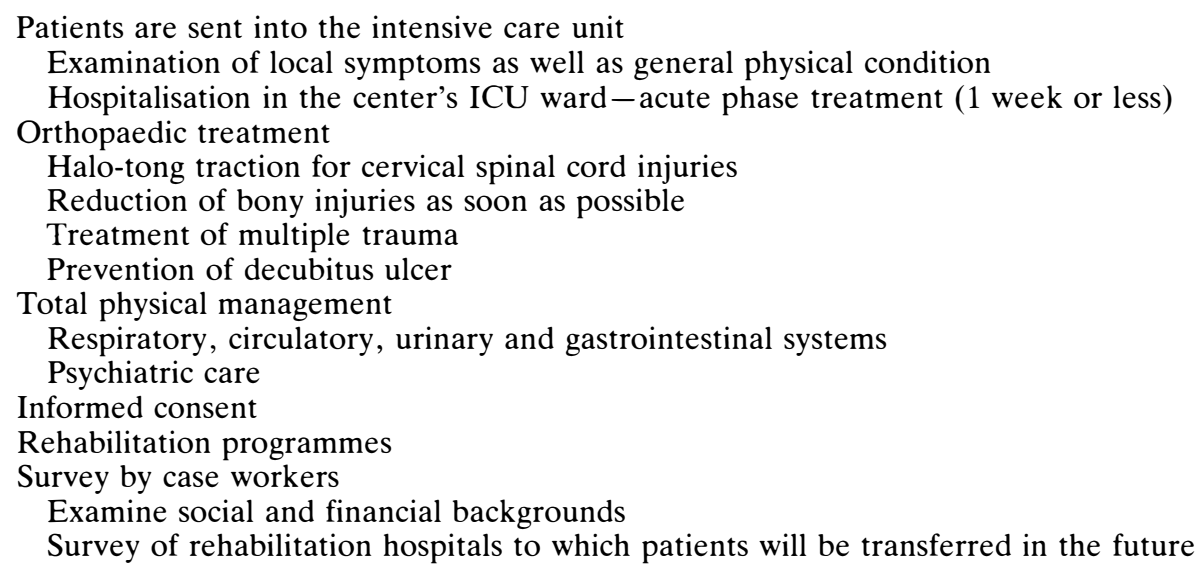

spinal bone injuries and performing reduction as early as possible. Generally speaking, patients are transferred to other hospitals after 3 months. However, patients with serious symptoms are forced to receive long term treatment in private rooms (Table V). ${ }^{2,3}$

The characteristics of group A patients hospitalised for 6 months or more include higher segment injuries of the cervical spinal cord, complete paralysis, respiratory complications such as pneumonia, or having had a tracheotomy. The pathology of these patients makes a transfer to other hospitals difficult. There is also the problem of inadequate facilities, ie the lack of the capacity to accommodate such patients.

Some problems of treating CSCI in university hospitals include the long term use of private rooms by severely injured patients, and the difficulty in transferring such patients to rehabilitation hospitals. Serious problems cited by patients and their families include the financial and psychological burden, the frustration of patients themselves due to extended hospitalisation, and the hospital's recommendations for home remodelling to enable hospital discharge. ${ }^{4}$
The following measure may be considered to improve the situation: the expansion of facilities for cervical spinal cord injuries; training of medical professionals such as doctors, nurses and physiotherapy staff; promotion of consistent treatment starting in the acute phase; development of a central control system for the accommodation of CSCI patients; and assertive national and prefectural policies toward these patients.

\section{Conclusions}

1 The problems of cervical spinal injury patients hospitalised in university hospitals for 3 months or more have been investigated.

2 The patients hospitalised for 6 months or longer, in particular, were characterised by having an injury at a high spinal cord level, complete paralysis, and complications such as pneumonia. These features are considered factors which make transfer to other hospitals difficult.

3 Assertive measures at the national and prefectural levels are called for in the future, such as an expansion of facilities.

\section{References}

1 Arima T (1982) Operative method for fresh dislocation of cervical spine. Orthop Surg (Japanese), Suppl 2: 281-284. 
2 Arima T (1991) Acute stage treatment for cervical spinal injuries in sport, complicating with complete or incomplete spinal cord injury. J. Clin Sports Med (Japanese) 8: 993-997.

3 Konagai A, Arima T, Mochida J (1991) Acute-phase treatment for cervical spinal cord injury in our University Hospital. J Jpn Paraplegia Med Assoc (Japanese) 4: 234-235.

4 Nagata M (1992) Rehabilitation for spinal cord injury. Brain Nursing (Japanese) '92 Suppl: 250-260. 